Edukids 16 (1), 2019

EDUKIDS: Jurnal Pertumbuhan, Perkembangan, dan Pendidikan Anak Usia Dini

Jln. Dr. Setiabudhi No. 229 Kota Bandung 40154. e-mail: edukid @upi.edu

website: http://ejournal.upi.edu/index.php/edukid

\title{
KEMAMPUAN GURU PAUD DALAM MENATA LINGKUNGKUNGAN BELAJAR DITINJAU DARI KUALIFIKASI AKADEMIK
}

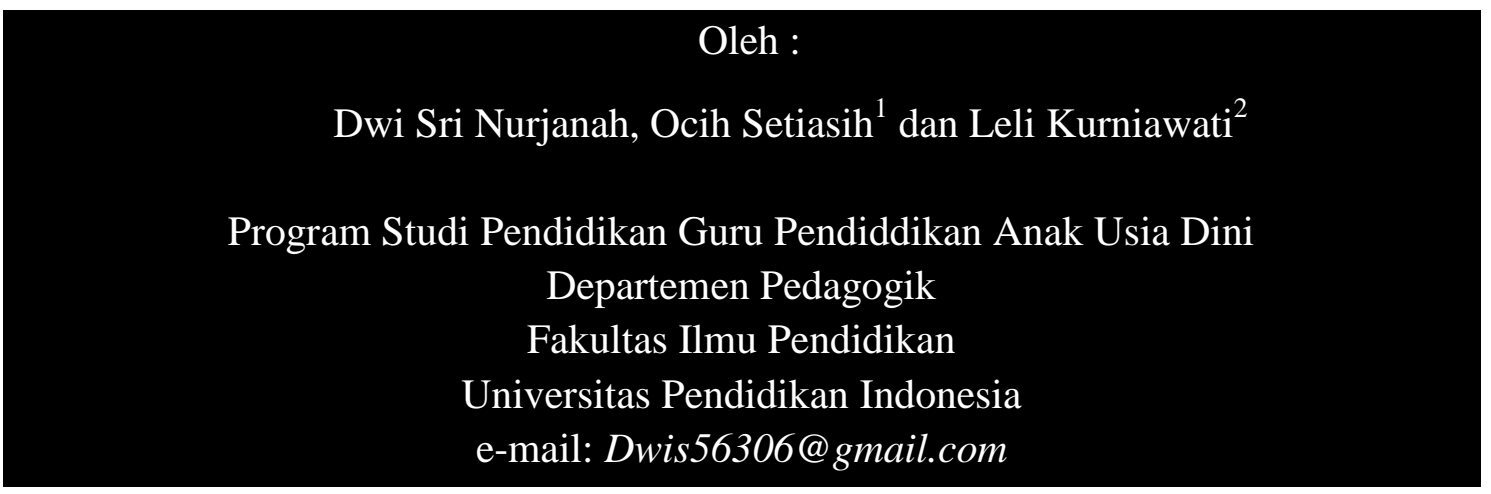

\begin{abstract}
Abstrak: Penelitian ini bertujuan untuk mengetahui perbedaan pengetahuan guru PAUD dalam menata lingkungan belajar antara guru yang berlatar belakang pendidikan relevan dengan PAUD dan yang berlatar belakang tidak relevan dengan bidang PAUD. Oleh karena itu penelitian ini menggunakan pendekatan kuantitatif dengan metode ex-post facto. Tes dilakukan kepada guru PAUD di Kecamatan Lengkong Kota Bandung yang berjumlah 50 orang yang tersebar di 7 PAUD/TK. Instrumen pengumpulan data mengacu pada rusman (2012) serta dikembangkan dan disesuaikan oleh peneliti. Analisis statistik untuk mengetahi perbedaan pengetahuan guru PAUD dalam menata lingkungan belajar menggunakan uji statistik Independent Sample T-test. Hasil penelitian ini yaitu 1) Profil pengetahuan guru PAUD dalam menata lingkungan belajar yang berlatar belakang pendidikan relevan dengan PAUD berada pada kategori sangat tinggi yaitu 93,33\% . 2) Profil pengetahuan guru PAUD dalam menata lingkungan belajar yang berlatar belakang pendidikan tidak relevan dengan PAUD berada pada kategori sangat tinggi yaitu 75\%. 3) Terdapat perbedaan yang signifikan $(\mathrm{p}=0,000<0,05)$ antara guru yang berlatar belakang pendidikan yang relevan dan tidak relevan dengan bidang PAUD. Hal ini menunjukan bahwa kualifikasi akademik menjadi salah satu faktor yang dapat mempengaruhi pengetahuan guru dalam menata lingkungan belajar. Berdasarkan hasil penelitian ini, maka peneliti merekomendasikan agar guru PAUD dapat memenuhi latar belakang pendidikan sesuai dengan standar yang berlaku guna meningkatkan pengetahuan dalam menata lingkungan belajar.
\end{abstract}

Kata Kunci: kualifikasi akademik, kemampuan guru menata lingkungan belajar 



\begin{abstract}
This research is based on empirical findings in kindergarten (TK), which shows that many children in their early childhood are lacking in building new knowledge by their experience. This is one of the causes of children's inadequate knowledge in the concept of science learning. It is also influenced by implementation of experimental-based science learning methods that are still rare, such as conducting a simple experiment. This study aims to see the effect of science learning process skills on early childhood before and after using experimental-based science learning methods. This research was conducted on early childhood groups B, in Laboratory UPI Bandung Kindergarten. Learning through experience in early childhood is expected to make it easier for children to get the real and new knowledge for them. This study uses a quantitative approach with a quasi-experimental design method, or Nonequivalent Control Group Design with the checklist as research instrument. This study used a sample of 18 people, consisting of one control group and one experimental group from two B classes in the kindergarten. The results showed $\mathrm{p}<$ 0.05 , which means that there are significant differences in science process skills between the control group and the experimental group. The results of the study after conducting experimental science-based learning with an average score increased in the control group, which is $71.95 \%$, while the experimental group reached $94.70 \%$. It can be concluded from the results that experimental-based science learning has a positive influence on science process skills in early childhood.
\end{abstract}

\title{
Keywords: academic qualifications, teachers' ability in organizing learning environment
}

\section{PENDAHULUAN}

Pendidikan merupakan kunci utama untuk menciptakan sumber daya manusia yang berkualitas, Hal ini ditegaskan oleh Purwanto (2007: hlm. 35) "bahwa Pendidikan adalah suatu wadah untuk mencerdaskan kehidupan bangsa, begitu pula dengan pendidikan anak usia dini yang merupakan peletak dasar pendidikan dari setiap individu." Pendidikan memegang peranan penting bagi setiap manusia begitu pula dengan pendidikan anak usia dini yang menjadi awal pondasi pendidikan.

Anak usia dini mempunyai hak pendidikan yang layak sesuai dengan kemampuan yang dimilikinya. Pengalaman belajar anak yang dimiliki akan melekat kuat dalam dirinya hingga dewasa. Oleh karena itu anak perlu berada dalam lingkungan belajar yang baik. Anak usia dini akan belajar dengan baik apabila guru menyediakan lingkungan belajar yang sesuai dengan kebutuhan anak, agar anak dapat mengekspresikan dirinya secara bebas, contohnya guru memberikan area bermain musik/bermain peran dengan kondisi lingkungan belajar yang memadai, dengan demikian anak dapat mengembangkan bakat dan minatnya. Hal ini ditegaskan oleh Sidi (2005: hlm. 148-150), "dalam menata lingkungan belajar di kelas yang menarik minat dan menunjang aktivitas anak dalam pembelajaran erat kaitannya dengan keadaan lingkungan fisik."

Menata lingkungan belajar yang akan digunakan dalam pembelajaran anak usia dini tentunya harus mempertimbangkan kebutuhan anak seperti pemilihan bahan, manfaat atau kegunaan, ukuran, warna dan bentuk. Menata lingkungan belajar juga penting bagi proses pembelajaran anak karena itu pembelajaran untuk anak sebaiknya memiliki ruangan yang nyaman agar proses pembelajaran dapat terlaksana dengan baik, menata lingkungan belajar 
yang baik dapat mengurangi kesempatan terjadinya gangguan kebosanan. Lingkungan belajar yang baik akan mendukung anak untuk dapat mengikuti pembelajaran dengan baik, sedangkan lingkungan belajar yang kurang baik akan membuat anak tidak nyaman ketika belajar, bahkan menimbulkan masalah-masalah ketika belajar. Selain itu juga guru dapat menciptakan lingkungan belajar yang menarik dan mampu membangkitkan semangat belajar anak.

Guru sebaiknya melibatkan anak secara aktif dalam proses pembelajaran, mengkondisikan lingkungan yang kondusif, serta mendorong anak bertanggung jawab atas perilaku yang dilakukan. Jika guru mampu mengendalikan proses pembelajaran dalam suasana yang kondusif, maka tujuan pembelajaran sebagaimana yang diharapkan dapat tecapai.

Suatu kelas tidak bisa berjalan dengan baik apabila guru dalam menata lingkungan belajar tidak sesuai dengan kebutuhan anak usia dini. Dengan demikian, pada praktiknya masih banyak ditemui guru-guru yang terkesan tidak peduli dalam menata lingkungan belajar. Misalnya masih ada guru yang menjalankan fungsinya sebagai pemimpin dalam kelas saja yang hanya datang memberikan tugas tanpa memperhatikan keadaan kelas, dan juga ventilasi udara, pencahayaan dalam kelas yang tidak diperhatikan oleh guru pada saat proses pembelajaran. Hal ini tentunya juga tidak sesuai dengan tujuan pendidikan yang ingin diraih. Kemampuan guru dalam menata lingkugan belajar merupakan faktor utama yang menentukan dalam menumbuhkan suasana belajar mengajar yang efektif. Selain itu, juga dapat memberi motivasi kepada anak sesuai dengan kemampuan dan karakter anak. Fungsi guru dalam menata lingkungan belajar sangatlah penting dan mendasar karena untuk merancang kegiatan pembelajaran menjadi lebih menyenangkan. Selain itu, menata lingkungan belajar sangat penting bagi guru karena akan mendukung tingkat kinerja guru dalam pelaksanaan proses pembelajaran di kelas. Hal ini ditegaskan juga oleh Mariyana (2010: hlm. 27) "guru mampu menguasai ruang lingkup pembelajaran guna mengetahui perkembangan anak sehingga tujuan permbelajaran yang baik dapat tercapai".

Salah satu aspek penting keberhasilan dalam proses pembelajaran adalah dari guru itu sendiri. Adapun faktor- faktor yang mepengaruhui tingkat kinerja guru menurut Cooper (2010: hlm. 34) yaitu: (a) tingkat pendidikan guru; (b) kegiatan penataran yang diikutinya dan (c) kondisi iklim yang kondusif. Dengan demikian pernanan guru pada proses pembelajaran sebaiknya bisa meguasai materi tentang penataan lingkungan belajar hal ini tentunya bisa kita tinjau dari latar belakang kualifikasi pendidikan guru. Untuk dapat menjalankan fungsinya dengan baik, guru wajib memiliki syarat tertentu, diantaranya adalah kualifikasi pendidikan di bidang pendidikan anak usia dini, kependidikan lain atau psikologi, dan sertifikasi profesi guru untuk PAUD.

Undang-Undang (UU) Nomor 20 Tahun 2003 tentang Sistem Pendidikan Nasional pasal 42 menyatakan "bahwa pendidik harus memiliki kualifikasi minimum dan sertifikasi sesuai dengan jenjang kewenangan mengajar, sehat jasmani, rohani, serta memiliki kemampuan untuk mewujudkan tujuan pendidikan nasional. PeraturanPemerintah (PP) Nomor 19 Tahun 2005 tentang Standar Nasional Pendidikan, pasal 28 disebutkan bahwa 
pendidik memiliki kualifikasi akademik dan kompetensi sebagai agen pembelajaran, sehat jasmani dan rohani,serta memiliki kemampuan untuk mewujudkan tujuan pendidikan nasional." Upaya pemerintah dalam meningkatkan kualifikasi pendidikan bagi guru tidak hanya sekedar gelar sarjana saja tetapi untuk meningkatkan wawasan bagi guru, sehingga guru dapat menata lingkungan belajar dengan baik.

Dari sudut pandang kualifikasi, indikator kompetensi guru dapat diukur berdasarkan sertifikat/ijazah yang dimiliki oleh guru yang bersangkutan. Dapat ditunjukan secara fungsional, yaitu kemampuannya dalam menata lingkungan belajar. Jadi kualifiksi pendidikan seorang guru harus berbanding lurus dengan kemampuannya.

Pada penelitian sebelumnya tentang perbedaan kemampuan guru dalam pengelolaan kelas di SD Minormartani 2 dilihat dari latar kualifikasi akademik oleh Ervina Puspitaningrum (2011). Menjelaskan bahwa terdapat perbedaan antara guru yang berlatar belakang SLTA dan S1 di SD Minomatani 2 Yogyakarta.

Diperkuat oleh penlitian yang dilakukan Sugini tahun 2011 menunjukan bahwa terdapat hubungan secara signifikan antara kualfikasi akdemik guru dengan pola manajemen kesiswaan di Taman Kanak-Kanak SeKecamatan Paguyangan.

Mengacu pada beberapa hasil penelitian dan pemaparan latar belakang di atas, penelitian yang akan dilakukan oleh peneliti berbeda dengan penelitan sebelumnya yaitu meneliti hal tentang latar belakang pendidikan dan kaitanya dengan kemampuan guru $\mathrm{Tk}$ dalam menata lingkungan belajar. Untuk menjawab apakah ada perbedaan kemampuan menata lingkungan belajar guru TK ditinjau dari latar belakang pendidikannya, diperlukan penelitian lebih lanjut, maka penulis tertarik untuk mengkaji lebih dalam melalui penenlitian yang berjudul "Kemampuan Guru PAUD dalam Menata Lingkungan Belajar Ditinjau dari Kualifikasi Akademik"

Rumusah masalah dari penelitian ini yaitu :

1. Seperti apa profil kemampuan guru PAUD dalam menata lingkungan belajar di Kecamatan Lengkong Kota Bandung ditinjau dari kualifikasi akademiknya?

2. Seperti apa profil kualifikasi akademik Guru PAUD di Kecamatan Lengkong Kota Bandung?

3. Apakah terdapat perbedaan kemampuan guru PAUD dalam menata lingkungan belajar di Kecamatan Lengkong Kota Bandung yang memiliki ijazah terakhir S1 yang relevan dengan PAUD dan S1 yang tidak relevan dengan PAUD?

\section{METODE}

Metode yang digunakan dalam penelitian ini adalah metode ex post facto atau disebut juga sebagai penelitian kausal kompratif. Penelitian ex post facto adalah penelitian yang meneliti hubungan sebab-akibat yang tidak dimanipulasi atau diberi perlakuan (dirancang dan dilaksanakan) oleh peneliti (Sukmadinata, 2015: hlm. 55).

Melalui penggunaan metode ini, peneliti ingin mengetahui bahwa pada dasarnya beberapa kelompok mempunyai perbedaan pada beberapa variabel dan peneliti berusaha mengindentifikasi faktor utama yang menjadi penyebab perbedaan tersebut. Metode ex post facto digunakan untuk mengetahui gambaran mengenai profil latar belakang pendidikan guru PAUD ditinjau dari kualifikasi akademik. 
Komparasi dalam penelitian ini terdiri dari satu model dengan komparasi dua sampel, yaitu : kemampuan guru PAUD dalam menata lingkungan belajar ditinjau dari latar belakang pendidikan guru PAUD yang relevan dan tidak relevan dengan bidang PAUD.

\section{HASIL DAN PEMBAHASAN}

Adapun penyajian data hasil penelitian berkenaan 1) Profil Kemampuan Guru PAUD dalam menata lingkungan belajar; 2) profil kualifikasi akademik Guru PAUD di Kecamatan Lengkong Kota Bandung ; 3) perbedaan Profil kemampuan Guru PAUD di Kecamatan Lengkong ditinjau dari kualifikasi akademiknya. Hasil penelitian tersebut dapat disajikan sebagai berikut:

\section{Profil Kemampuan Guru PAUD di Kecamatan Lengkong Kota Bandung ditinjau dari Kualifikasi Akdemiknya}

Profil kemampuan guru PAUD yang dimaksud dalam penelitian ini adalah sejauh mana tingkat pengetahuan guru dalam menata lingkungan belajar. Profil kemampuan guru dalam menata lingkungan belajar tersebut kemudian dikategorikan kedalam tiga tingkatan yaitu tinggi, sedang, rendah. Pengkategorisasian tersebut ini diperoleh melalui pengkategorisasian skor ideal.

Berdasarkan hasil penelitian terhadap 30 guru yang memiliki ijazah terakhir yang relevan dengan bidang PAUD diperoleh bahwa profil kemampuan guru PAUD dalam menata lingkungan belajar yang berada pada tingkat tinggi berjumlah 28 guru, kategori sedang berjumlah dua dan tidak terdapat guru yang memiliki kategori rendah. Adapun profil kemampuan guru yang memiliki ijazah terakhir S1 yang relevan dengan bidang PAUD memiliki jumlah skor paling besar berada pada kategori tinggi dengan jumlah skor 22 berjumlah 1 guru, dan jumlah skor pada kategori sedang dengan jumlah skor 19 berjumlah 2 guru dan tidak ada guru yang memiliki kategori rendah.

Berdasarkan hasil penelitian terhadap 20 guru yang memiliki ijazah terakhir S1 yang tidak relevan dengan bidang PAUD diperoleh bahwa kemampuan guru dalam menata lingkungan belajar yang berada pada tingkat tinggi berjumlah 15 kategori sedang berjumlah empat guru dan kategori rendah satu guru. Adapun profil kemampuan guru PAUD dalam menata lingkungan belajar yang memiliki ijazah terakhir S1 yang tidak relevan dengan bidang PAUD memiliki jumlah skor paling besar berada pada kategori tinggi dengan jumlah skor 20 berjumlah satu guru, sedangkan jumlah skor paling rendah berada pada kategori rendah dengan jumlah skor 4 berjumlah 2 guru. Adapun lebih jelasnya profil kemampuan guru dalam menata lingkungan belajar yang dikelompokan .

Berdasarkan kategorinya adalah sebagai berikut: 


\begin{tabular}{|c|c|c|c|c|c|}
\hline \multirow{2}{*}{$\begin{array}{l}\text { Kate } \\
\text { gori }\end{array}$} & \multirow{2}{*}{$\begin{array}{l}\text { Inter } \\
\text { val }\end{array}$} & \multicolumn{2}{|c|}{ Frekuensi } & \multicolumn{2}{|c|}{ Presentase $(\%)$} \\
\hline & & $\begin{array}{l}\mathrm{S} 1 \\
\text { yang } \\
\text { releva } \\
\mathrm{n} \\
\text { denga } \\
\mathrm{n} \\
\text { bidan } \\
\mathrm{g} \\
\text { PAU } \\
\mathrm{D}\end{array}$ & $\begin{array}{l}\text { S1 } \\
\text { yang } \\
\text { tidak } \\
\text { relev } \\
\text { an } \\
\text { deng } \\
\text { an } \\
\text { bida } \\
\text { ng } \\
\text { PAU } \\
\text { D }\end{array}$ & $\begin{array}{l}\mathrm{S} 1 \\
\text { yang } \\
\text { releva } \\
\mathrm{n} \\
\text { denga } \\
\mathrm{n} \\
\text { bidan } \\
\mathrm{g} \\
\mathrm{PAU} \\
\mathrm{D}\end{array}$ & $\begin{array}{l}\text { S1 yang } \\
\text { tidak } \\
\text { relevan } \\
\text { dengan } \\
\text { bidang } \\
\text { PAUD }\end{array}$ \\
\hline $\begin{array}{c}\text { Ting } \\
\text { gi }\end{array}$ & $\begin{array}{c}16- \\
23 \\
\end{array}$ & 28 & 15 & $\begin{array}{l}93, \\
33\end{array}$ & 75 \\
\hline $\begin{array}{c}\text { Seda } \\
\text { ng }\end{array}$ & $\begin{array}{l}8- \\
15\end{array}$ & 2 & 4 & 6,67 & 20 \\
\hline $\begin{array}{c}\text { Rend } \\
\text { ah }\end{array}$ & $0-7$ & 0 & 1 & 0,00 & 5 \\
\hline \multicolumn{2}{|c|}{ Jumlah } & 30 & 20 & $\begin{array}{l}100, \\
00\end{array}$ & 100,00 \\
\hline
\end{tabular}

Tabel 4.1

Profil Kemampuan Guru PAUD dalam Menata Lingkungan Belajar yang Memiliki Ijazah Terakhir S1 yang Relevan dengan Bidang PAUD dan S1 yang Tidak Relevan dengan Bidang PAUD

Bila digambarkan dalam bentuk grafik, maka profil kemampuan guru PAUD dalam menata lingkungan belajar disajikan seperti pada grafik berikut :

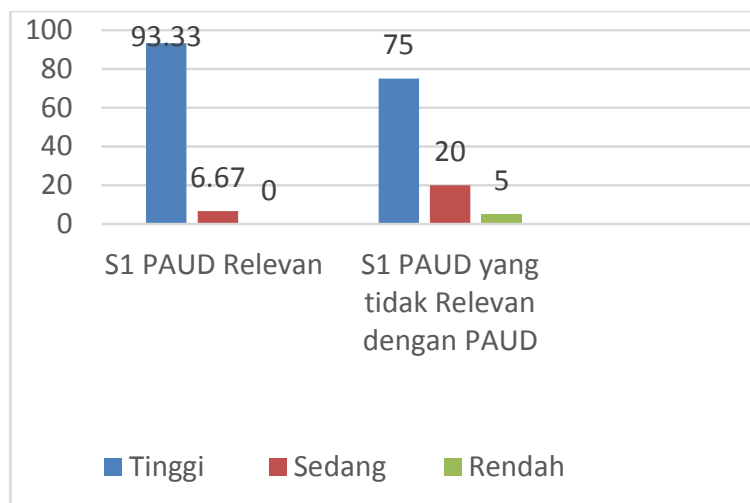

Grafik 4.1: Profil Kemampuan Guru PAUD dalam Menata Lingkungan Belajar yang Memiliki Ijazah S1 yang Relevan dengan Bidang PAUD dan S1 yang Tidak Relevan dengan Bidang PAUD

Grafik di atas menunjukkan bahwa profil kemampuan guru PAUD dalam menata lingkungan belajar di Kecamatan Lengkong Kota Bandung dengan jumlah presentase guru yang memiliki ijazah S1 yang relevan dengan bidang PAUD paling banyak adalah 93, $33 \%$ yaitu berada pada kategori tinggi dan paling sedikit $6,67 \%$ yaitu berada pada ketegori sedang. Sedangkan profil kemapuan guru yang memiliki ijazah S1 yang tidak relevan dengan bidang PAUD memiliki presentase paling banyak $75 \%$ yaitu berada pada kategori tinggi, kemudian paling sedikit adalah $5 \%$ yaitu berada pada ketegori rendah, dan $20 \%$ pada kategori sedang. Dengan demikian, dapat diketahui bahwa profil kemampuan guru PAUD di Kecamatan Lengkong kota bandung yang memiliki ijazah terakhir S1 yang relevan dengan bidang PAUD dan S1 yang tidak relevan dengan bidang PAUD sebagian besar sudah baik, karena presentase profil keduanya sudah tinggi, walaupun pada guru yang memiliki ijazah terakhir S1 yang tidak relevan dengan bidang PAUD ada yang memiliki kategori rendah.

\section{Profil Kualifikasi Akademik Guru PAUD di Kecamatan Lengkong Kota Bandung}

Hasil penelitian diperoleh dari 50 sampel guru-guru PAUD yang tersebar di 7 PAUD di Kecamatan Lengkong Kota Bandung. Lebih rinciannya sebaran sampel guru PAUD tersebut berdasarkan ijazah terakhirnya adalah sebagai berikut: 
Tabel 4.3: Sebaran Sampel Guru PAUD

\begin{tabular}{|c|c|c|c|c|}
\hline \multirow[b]{2}{*}{ No. } & \multirow[b]{2}{*}{ Kelurahan } & \multicolumn{2}{|c|}{ Jumlah Guru } & \multirow[b]{2}{*}{$\begin{array}{c}\mathrm{Ju} \\
\mathrm{ml} \\
\mathrm{ah}\end{array}$} \\
\hline & & $\begin{array}{l}\text { S1 } \\
\text { PGPA } \\
\text { UD dan } \\
\text { Psikolo } \\
\text { gi }\end{array}$ & $\begin{array}{l}\text { S1 } \\
\text { yang } \\
\text { tidak } \\
\text { releva } \\
\mathrm{n} \\
\text { denga } \\
\mathrm{n} \\
\text { bidan } \\
\mathrm{g} \\
\text { PAU } \\
\mathrm{D}\end{array}$ & \\
\hline 1. & Burangrang & 8 & 7 & 15 \\
\hline 2. & Cijagra & 5 & 3 & 8 \\
\hline 3. & Cikawao & 3 & 2 & 5 \\
\hline 4. & $\begin{array}{l}\text { Lingkar } \\
\text { selatan }\end{array}$ & 6 & 4 & 10 \\
\hline 5. & Malabar & 2 & 1 & 3 \\
\hline 6. & Paledang & 5 & - & 5 \\
\hline 7. & Turangga & 1 & 3 & 4 \\
\hline & Total & 30 & 20 & 50 \\
\hline
\end{tabular}

\begin{tabular}{|l|l|r|r|c|c|}
\hline Kelompok & $\mathrm{N}$ & $\begin{array}{c}\text { Me } \\
\text { an }\end{array}$ & $\begin{array}{c}\text { Std. } \\
\text { Devi } \\
\text { ation }\end{array}$ & $\begin{array}{c}\text { Std. } \\
\text { Error } \\
\text { Mean }\end{array}$ \\
\hline $\begin{array}{l}\text { S1 yang } \\
\text { Relevan } \\
\text { dengan }\end{array}$ & 30 & 20, & 1,358 & 0,247 \\
$\mathrm{~N}$ & $\begin{array}{l}\text { PAUD } \\
\text { il }\end{array}$ & & & \\
S1 yang & $\begin{array}{l}\text { Tidak } \\
\text { Relevan } \\
\text { dengan } \\
\text { PAUD }\end{array}$ & 20 & 18, & 1,899 & 0,424 \\
\hline
\end{tabular}

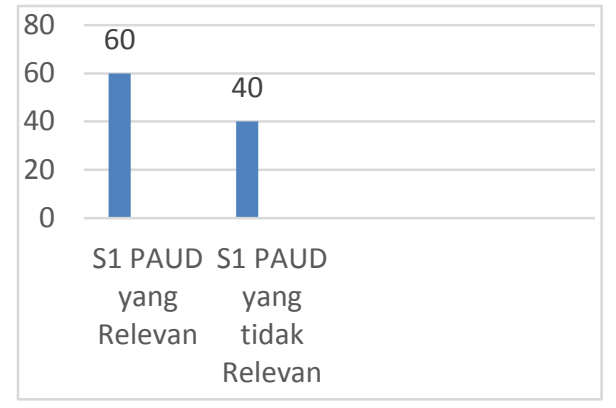

Grafik 4.5:

Kualifikasi Akademik Guru

Dari grafik di atas dapat disimpulkan bahwa kualifikasi akademik guru PAUD di Kecamatan Lengkong Kota

Bandung memiliki penyebaran guru yang hampir seimbang antara guru yang memiliki ijazah terakhir S1 yang relevan dengan bidang PAUD dan S1 yang tidak memiliki ijazah S1 yang tidak relevan dengan bidang PAUD, yaitu dengan persentase $60 \%$ artinya guru-guru PAUD di Kecamatan Lengkong sudah memenuhi standar kualifikasi akademik walaupun masih banyak yang tidak relevan dengan bidang PAUD.

Dari data hasil uji $\mathrm{t}$ yang telah dilakukan dapat disimpulkan bahwa terdapat perbedaan kemampuan guru dalam menata lingkungan belajar pada guru yang memiliki ijazah terakhir S1 yang relevan dengan bidang PAUD dan S1 yang tidak relevan dengan bidang PAUD. Untuk membuktikan kelompok manakah yang lebih unggul, digunakan group statistic sebagai berikut: 


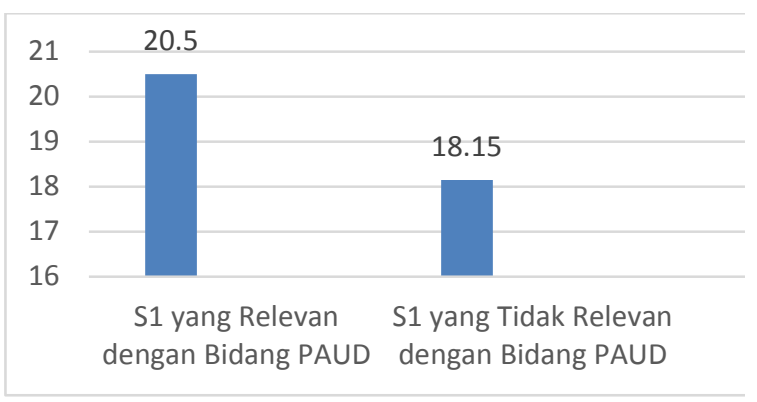

Tabel 4.6

Group Statistik

Apabila digambarkan dalam bentuk grafik, maka rata-rata data kemampuan guru PAUD dalam menata lingkungan belajar yang memiliki ijazah terakhir S1 yang relevan dengan bidang PAUD dan S1 yang tidak relevan dengan bidang PAUD, disajikan sebagai berikut

Berdasarkan grafik 4.6 dapat disimpulkan bahwa profil kemampuan guru PAUD dalam menata lingkungan belajar yang memiliki ijazah S1 yang relevan dengan bidang PAUD memiliki rata-rata 20,5 lebih besar dari pada ratarata profil kemampuan guru PAUD dalam menata lingkungan belajar yang memiliki ijazah S1 yang tidak relevan dengan bidang PAUD yaitu sebesar 18,15. Hal ini dapat diartikan bahwa profil kemampuan guru PAUD dalam menata lingkungan belajar yang tinggi dimiliki oleh kelompok guru yang memiliki ijazah terakhir S1 yang relevan dengan bidang PAUD.

\section{DAFTAR PUSTAKA}

$\begin{array}{crr}\text { Cooper. } \quad(2010) . & \text { Dari } & \text { Guru } \\ \text { Konvensional } & \text { Menuju } & \text { Guru } \\ \text { Profesioanal. } & \text { Jakarta: } & \text { PT. } \\ \text { Grasindo. 105 } & & \end{array}$

Mariyana, R, Nugraha, A., Rachmawati, Y. (2010). Pengelolaan Lingkungan Belajar. Jakarta: Kencana Prenada Media Group.
Peraturan Mentri Pendidikan Nasional Nomor 19 Tahun 2005 tentang Standar Nasional Pendidikan

Purwanto, M.I (2007) Menciptakan Lingkungan yang Positif untuk Pembelajaran. Magistra. Hlm. 35

Puspita E, N. (2011) pengelolaan kelas di SD Minormartani 2 dilihat dari latar kualifikasi akademik. Skripsi

Sidi, (2005). Tata Ruang Kelas Anak. Jakarta: Raja Grafindo. Hlm. 148150

Sugini. (2011). Kualifikasi Guru dengan Pola Manajemen Kesiswaan. Skripsi

Sukmadinata, Nana S. (2015). Metode Penelitian Pendidikan. Bandung: PT Remaja Rosdakarya.

Undang-Undang (UU) Nomor 20 Tahun 2003 tentang Sistem Pendidikan Nasional 